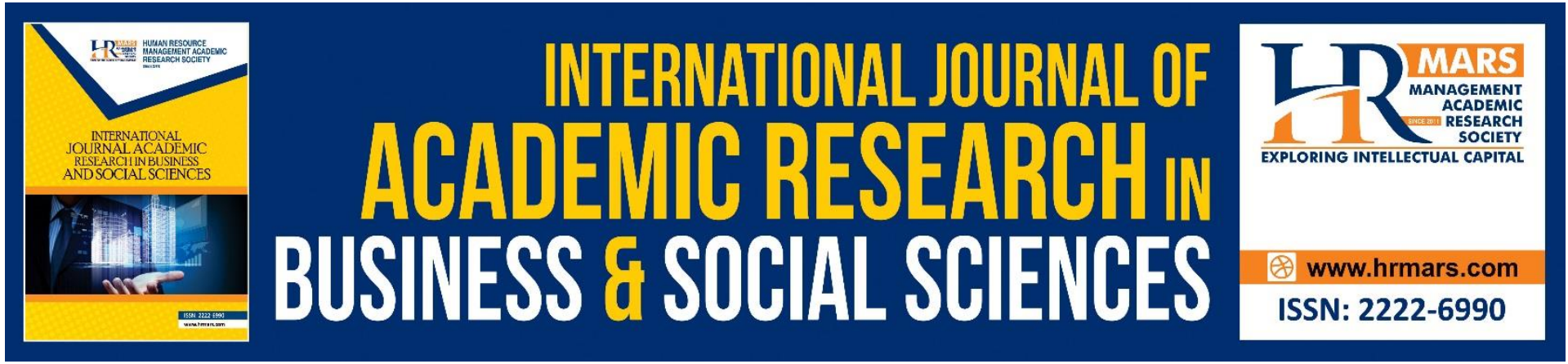

\title{
The Relationship Between Technostress Creator and Work- Life Balance at Selected Private Sector in Selangor
}

\author{
Mohammad Amir Shah Saim, Wan Edura Wan Rashid, Siti Noorsuriani \\ Ma'on
}

To Link this Article: http://dx.doi.org/10.6007/IJARBSS/v11-i6/10389 DOI:10.6007/IJARBSS/v11-i6/10389

Received: 14 April 2021, Revised: 18 May 2021, Accepted: 02 June 2021

Published Online: 26 June 2021

In-Text Citation: (Saim et al., 2021)

To Cite this Article: Saim, M. A. S., Rashid, W. E. W., \& Ma'on, S. N. (2021). The Relationship Between Technostress Creator and Work-Life Balance at Selected Private Sector in Selangor. International Journal of Academic Research in Business and Social Sciences, 11(6), 1636-1650.

Copyright: (c) 2021 The Author(s)

Published by Human Resource Management Academic Research Society (www.hrmars.com)

This article is published under the Creative Commons Attribution (CC BY 4.0) license. Anyone may reproduce, distribute, translate and create derivative works of this article (for both commercial and non-commercial purposes), subject to full attribution to the original publication and authors. The full terms of this license may be seen at: http://creativecommons.org/licences/by/4.0/legalcode

Vol. 11, No. 6, 2021, Pg. 1636 - 1650

http://hrmars.com/index.php/pages/detail/IJARBSS

JOURNAL HOMEPAGE

Full Terms \& Conditions of access and use can be found at http://hrmars.com/index.php/pages/detail/publication-ethics 


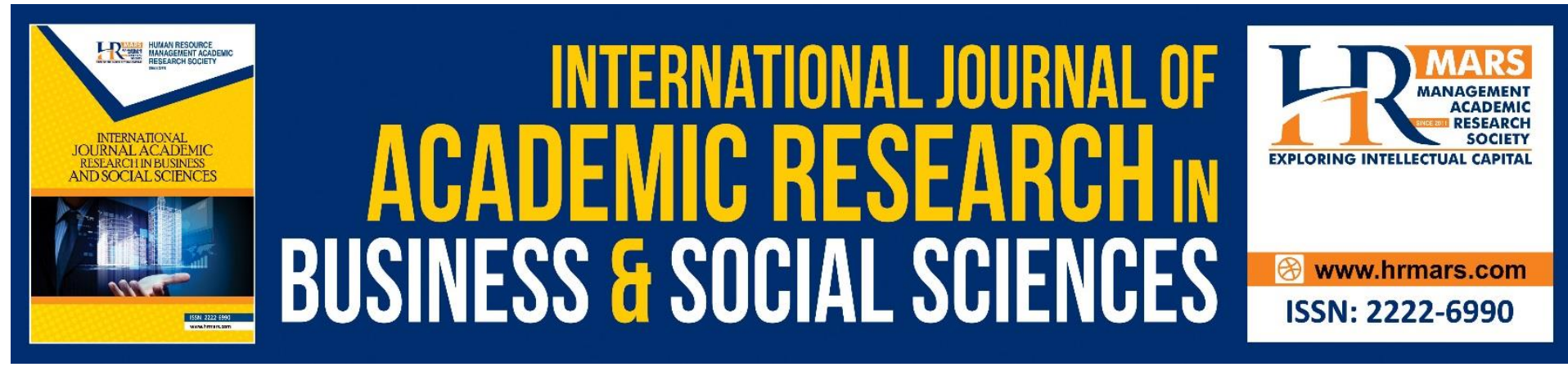

\title{
The Relationship Between Technostress Creator and Work-Life Balance at Selected Private Sector in Selangor
}

\section{Mohammad Amir Shah Saim ${ }^{1}$, Wan Edura Wan Rashid², Siti Noorsuriani Ma'on ${ }^{3}$}

${ }^{1}$ Faculty of Business Management, Universiti Teknologi MARA, Shah Alam, Selangor Malaysia, ${ }^{2}$ Institute of Business Excellence, Universiti Teknologi MARA, Shah Alam, Selangor Malaysia, ${ }^{3}$ Faculty of Business Management, Universiti Teknologi MARA Cawangan Selangor, Kampus Puncak Alam, Selangor Malaysia

Email: amirshah9463@gmail.com,wanedura@uitm.edu.my, sitinoor123@uitm.edu.my

\begin{abstract}
Work-life balance plays a critical role in every employee's life. It is undeniable that work-life balance is closely related to the best organization's optimal functioning. Maintaining worklife balance can help reduce stress, thus it prevents burn-out at work. At the same time, studies also show that employees may suffer technostress due to the inability to effectively use latest technology to manage their work. Therefore, the purpose of this study is to examine the relationship between work-life balance and technostress creator. A cross-sectional survey was conducted at selected private sectors in Selangor. A total of 153 data obtained was valid for data analysis. Both descriptive and inferential analyses were applied using IBM SPSS to examine the relationship between technostress creator and work-life balance. The findings showed technostress factors; including techno-overload, techno-invasion and technocomplexity have significant relationships with work-life balance of employees. Hence, organization must note the importance of assisting to maintain the work-life balance of employees in order to reduce technostress and sustain the less stressed and motivating working environment, because this will definitely help to improve work efficiency and productivity.
\end{abstract}

Keywords: Organization, Technology, Technostress Creator, Work-Life Balance.

\section{Introduction}

Every individual is an essential part of the family and society in general. In today's business world, work-life balance is a critical factor in the achievement of organizational objectives. Work-life balance should be a key concept to all employers today, especially to those with an increasing number of people in the organization and due to the additional demand for work that they imply. According to Greenhaus, Collins, and Shawn (2003), the best work-life balance situation is when an employer can manage work timetables and schedules for some leisure activities in a way that suits the employees. Managing both work 
and life aspects by ensuring a good relationship between them should be the primary objective. Employees try their best to remain in the organization by putting more time at work, which may be harmful to their personal life. Moreover, employees who do not have a proper work-life balance end up in conflict with peers and strained relationships with family members and depression (Foy et al., 2019). Hence, employers need to develop strategies that help employees balance their work and their personal lives with a changing pattern in working hours that is quite different from the standard one which usually operates from 9 a.m. to 5 p.m. That change will significantly impact employees' health which they need to work beyond the normal eight hours of work (Wong et al., 2020).

According to Kupersmith (1992), besides working eight hours in the office, employees also spent another seven hours per week working from home. Particularly for female employees, having the responsibility as a mother and wife at home, they are still required to perform various office operations online. They spend much time in the workplace and at home using computers. They use computers to browse the Internet, check messages, and interact with online colleagues regarding work. Technology that facilitates a higher workload on these individuals has developed a new phenomenon of a problem called technostress. Tools that can be used to perform work nowadays may include smartphones (Blackberry, Iphone, to name a few) and PC tablets (iPad, Galaxy tab, to name a few), and are no longer limited to computers.

Additionally, numerous PC-like working gadgets can be used these days (as stated above), making employees' work less complicated (Choi, Kim \& Cho, 2011). Sarabani, Carter, and Compeau (2020) also supported this statement about employees using technology to improve themselves to perform tasks. However, technology imposes a lot of pressure on them when managers expect them to work more quickly and do more for the organization.

As stated above, technostress is the term used to describe the stress phenomenon induced by the inability to manage using computer technology. Technostress is a common adaptation disorder caused by the failure to cope with new computer technology in a healthy manner (Geetanjali \& Rao, 2020). For example, in a study conducted by Caruso (2006), a long working hour with computer technology may associate employees with various risks such as sleep deprivation, illness and weak work recovery. Past studies have shown that employees are now struggling to deal with fast technology changes in work task performance (White, Behrend \& Siderits, 2020). Benamati (2001); Gallivan (2004) suggested that it would be valuable to carry out research to determine the extent of technology anxiety experienced by employees in business organizations.

In summary, in business organization the vital factor to sustain productivity and wellbeing of employee is work-life balance. Low work-life balance can affect organization performance and increase the rate of turnover in organization (Orwa \& Nyangau, 2020). Besides, previous studies have shown that work demands arising from technology at workplace will reduce their emotional well-being and work-life balance (Lutz, Schneider, \& Vorderer, 2020).

\section{Literature Review \\ Work-life Balance (WLB)}

Work-life balance (WLB) refers to understanding of individuals as to how well work and non-work activities match together and are handled by their system of life values, priorities and expectations (Capitano \& Greenhaus, 2018; Greenhaus, Ziegert \& Allen, 2012; Haar 2013). According to Thakur, Shah \& Bhat (2020), it is essential to understand that work- 
life balance does not simply mean the division of time that is spent on paid work and unpaid roles; in its broadest sense; it can also be interpreted as a satisfactory level of involvement or as a match between various parts in a person's life. Gragnano, Simbula and Miglioretti (2020) further added that work-life balance is the understanding that work and non-work activities are compatible with current life goals. The best work-life balance is when an employer can create work timetables to integrate leisure activities for the employees. Managing both work and life aspects by ensuring a good relationship between them should be the primary objective of life (Greenhaus., et al 2003). This statement was agreed by Okolo (2018) that an excellent work schedule is the one in which the employees have some control over the planning of shifts that it allows the reduction of family and career conflicts. However, worklife balance can be hard to accomplish for full-time workers especially those with childcare needs (Tan, 2019).

In the above context, consideration towards work location alternative is a critical factor for an employer to think about. Allowing work from home for instance, allows employees to manage work schedule optimally, and the possible reduction of work-family interference (Gajendran \& Harrison, 2007). However, another research claims that technologies have made them more productive at the workplace by making them more organized in some circumstances. The technology made it much less demanding to work longer hours. However, whether or not the effect of technology-assisted extra work on worklife balance is for the positive or negative result, it is still open for discussion (Derks et al., 2014).

\section{Technostress}

Technostress is a negative impact caused either directly or indirectly by dependency on technology on attitudes, thoughts, behaviours, or body physiology. Massive dependency on technology may adversely affect employees' life in various manners (Rosen \& Weil, 2002). Technostress can also be defined as a situation where the employer requirement towards employees to utilize technology for better task performance resulted in creating a lot of pressure, in terms of technology catching up and familiarization on them (Sarabadani, Carter \& Compeau, 2020). According to Craig (1984), technostress is a new disease of adaption caused by the inability to cope up and manage with the latest computer technologies healthily. This study addresses the adverse effect (anxiety and stress) caused by fear and struggle from the inability of use of technology through the observation of technostress nature.

Based on the psychological stress literature, technostress is conceptualized as a second-order construct consisting of three stress-creating variables known as technooverload, techno-invasion, and techno-complexity. The term technostress has been described as people's inability to use technology safely (Sarabadani et al., 2020). Most of the research on technostress focused on the relationship between technology usage and its associated strains. Significant studies in this field have investigated the negative impact of technology on employee satisfaction, performance, productivity and commitment (Sarabadani et al., 2020; Jena, 2015). Further, technostress creators and their impacts have also been examined in different contexts, such as usage of social networks, emails, smartphones, and the use of IT in general (Salo et al., 2018; Stich et al., 2019). These are new phenomena of technostress impact directly linked to employees due to computer technology usage. Bayer, Campbell and Ling (2015) have conducted a study that showed users feel uncomfortable to answer it 
immediately, especially when they are on holiday because this will mean spending extra time for work even though being away from the workplace.

\section{Techno-overload}

According to Tarafdar, Ragu-Nathan and Ragu-Nathan (2011), techno-overload is a situation where information systems usage forces professionals to work more and faster. They describe technology overload as an interruption to the daily life phase via massive insertion of information such as e-mail or any text-based message containing workflow that pressures users into attending to such information as soon as it arrives, thus, creating anxiety, tension and workflows disconnect. Such a situation makes sustaining mental attention becomes more difficult. Another definition would portray technology overload as a device proliferation or information overload that causes cognitive and physical burdens on human beings due to multiple gadgets with multiple functions to accomplish various tasks in everyday activities (Grandhi et al., 2005). Techno-overload reflects above all circumstances where the use of technology increases employee workload and forces them to work more quickly to achieve more in less time, encountering pressure and nervousness (Suh \& Lee, 2017). According to Okebaram and Moses (2013), the impact of techno-overload in the workplace is mostly noticeable when employees spend their extra time at workplace due to additional arrangement of work received through e-mail, voice messages, and web pages; to the point they have to sacrifice their time with family, friends and others. It is unfortunate that technologies adversely make employees become more dependent and constantly connected to work. The "overload" situation normally takes place when employees need to spend a lot of extra time in completing the demand of job tasks that mostly comes in last minute through the channels of information technology bring. Gradually, employees cannot manage their time more efficiently, hence decrease work-life balance (Ingusci et al., 2021).

\section{Techno-invasion}

Techno-invasion describes a situation where professionals can potentially be reached anywhere and anytime and feel the need to be continuously connected (Tarafdar et al., 2011; Lei \& Ngai, 2014). Ibrahim and Yusoff (2015) stated that techno-invasion refers to when users feel that they are never free from technology. They think that technology has invaded their lives. According to Tarafdar et al (2011), techno-invasion will create a situation where the average working day and time spent with family become imbalanced with work and employees worry about not being connected to their smartphones (and work) even during their holidays and vacations. This situation is especially relevant to the banking sector's employees as their official e-mail is automatically connected to their smartphone, resulting in work-family conflict as working hours penetrate personal family time. According to Raisiene and Jonusauskas (2013), organizations use modern technology to improve productivity, yet, at the cost of employees' work-life balance. For example, previous studies have shown that although email, mobile phones communication and other mobile devices are facilitating communication opportunities among individuals, associated with requirement to urgently perform tasks by employer, they may cause stress and make it easier for employees to ruin their work and private time separation. When the boundaries between work and non-work become blurred, the employee's quality of life and productivity may decrease (Murrary \& Rostis, 2007). 


\section{Techno-complexity}

According to Tarafdar et al (2011), techno-complexity is when the complexity associated with an information system is being learned the usage (of the new application) by the professionals through time and effort. As being competitive is necessary and vendor's pressures to continue using the latest app have increased, it requires technical capabilities and the terminology associated with the information system that have become more complex. The argument is close to Khan, Rehman and Rehman, (2013) who stated that it takes a month for the new application to be learned due to unfavourable and impenetrable manuals. Consequently, professionals or employees may feel stressed. On that note, technocomplexity could also mean employees feeling their technical skill level is inappropriate for effective performance.

Referring to the study by Necessari and Parish (2012), the effort done by employees to constantly learn about new technology in the workplace is paid by lesser private time they have to maintain a good work-life balance. Though technology may bring a positive impact to productivity though positive experience of the usage, techno-complexity on the other hand brings a negative impact on work-life balance as users are expected to be deprived of quality time through the extended usage experience of technology (Okolo, 2018). It is true that employees' spending time in learning a new system or technology may provide better satisfaction in the workplace, but it is at the cost of being almost impossible to disconnect from work and to have a clear work and life boundary that is essential to maintaining good personal health (Raisiene \& Jonusauskas, 2013).

\section{Research Framework}

Figure 1 indicates that independent variables are technostress creator; including techno-overload, techno-invasion and techno-complexity and dependent variable is work-life balance. Based on the research objectives, there have been three hypotheses formulated to be examined as stated below.

$\mathrm{H} 1$ : There is a significant relationship between techno-overload and work-life balance $\mathrm{H} 2$ : There is a significant relationship between techno-invasion and work-life balance H3: There is a significant relationship between techno-complexity and work-life balance

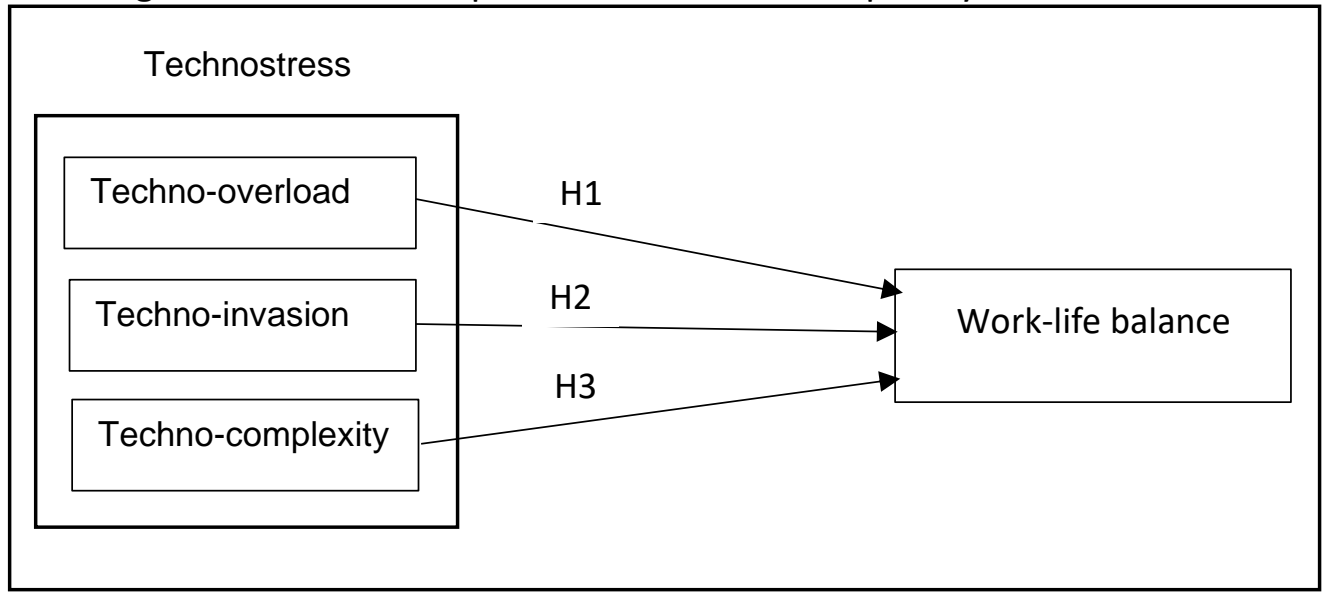

Figure 1. Proposed conceptual framework 


\section{Methodology}

This study employed a cross-sectional and correlational research design to examine the relationship between technostress creator and work-life balance. Using the convenience sampling technique, a survey instrument was designed and distributed to 200 respondents, who were employees from selected private sectors in Selangor. Employees were asked to rate their perceptions on the 5-point Likert scale; ranging from $1=$ 'Strongly Disagree' to $5=$ 'Strongly Agree'. Both descriptive and inferential statistics were applied in this study. Descriptive statistics (frequency analysis) were performed to describe the characteristics of the respondents, including age, gender, race, education level, marital status, and experience years of work in the organization. Prior to performing a correlation analysis, factor analysis and a reliability test on the variables were carried out. All the data obtained were analysed using the statistical package for social science software (IBM SPSS version 23.0).

\section{Results}

After a thorough data screening process, 153 of the 200 data obtained were valid for data analysis. Descriptive analysis, validity and reliability testing and correlational analysis will be explained in the following sections

\section{Descriptive Statistics}

A descriptive analysis was carried out to describe the demographic characteristics of the respondents. Table 1 summarises the demographic profile of respondents. The data findings showed that there more male respondents $(53.6 \% ; n=82)$ than female respondents $(46.4 \% ; n=71)$. Majority of respondents were Malay $(n=129 ; 84.3 \%)$ and nearly $16 \%$ were from other races; including Indian $(n=12 ; 7.8 \%)$, Chinese $(n=8 ; 5.2 \%)$ and others $(n=4 ; 2.7 \%)$. There were $40.5 \%$ respondents between 26 and 35 years old and $36.6 \%(n=56)$ respondents were below 25 years old. There were $15 \%$ respondents between 36 and 45 years old. Nearly $5 \%$ of the respondents were aged above 56 years old; $2.9 \%(n=9)$ were aged range between 46 and 55 years and $2 \%(n=3)$ were above 56 years old. Most of the respondents were married $(56.9 \%$ as compared to single $34.0 \%$ and divorced/separate $9.2 \%)$. About half of respondents were bachelor's degree holders $(n=81 ; 52.9 \%)$, followed by diploma holders $(26.8 \%)$ and $7.8 \%$ STPM leavers. Only $5 \%$ of respondents had received a postgraduate degree. Most respondents with less than two working years and below in the organization at $46.4 \%$, followed by respondents working 2 to 4 years in the organization at $24.2 \%$, while respondents working 5 to 7 years in the organization was $15.7 \%$, followed by respondents working 8 to 10 years was $10.5 \%$ and $3.3 \%$ have only worked for 11 years and above in the organization. 
Table 1. Respondents' demographic profiles $(\mathrm{N}=153)$

\begin{tabular}{|c|c|c|}
\hline Variable & $\begin{array}{c}\text { Frequency } \\
n\end{array}$ & $\begin{array}{c}\text { Percentage } \\
\%\end{array}$ \\
\hline \multicolumn{3}{|l|}{ Gender } \\
\hline Male & 82 & 53.6 \\
\hline Female & 71 & 46.4 \\
\hline \multicolumn{3}{|l|}{ Age } \\
\hline 25 years old and below & 56 & 36.6 \\
\hline 26-35 years old & 62 & 40.5 \\
\hline $36-45$ years old & 23 & 15.0 \\
\hline $46-55$ years old & 9 & 2.9 \\
\hline Above 56 years old & 3 & 2.0 \\
\hline \multicolumn{3}{|l|}{ Race } \\
\hline Malay & 129 & 84.3 \\
\hline Indian & 12 & 7.8 \\
\hline Chinese & 8 & 5.2 \\
\hline Others & 4 & 2.7 \\
\hline \multicolumn{3}{|l|}{ Education Level } \\
\hline STPM & 12 & 7.8 \\
\hline Diploma & 41 & 26.8 \\
\hline Bachelor Degree & 81 & 52.9 \\
\hline Master & 7 & 4.6 \\
\hline PhD & 1 & 0.7 \\
\hline \multicolumn{3}{|l|}{ Marital Status } \\
\hline Married & 87 & 56.9 \\
\hline Single & 52 & 34.0 \\
\hline Divorce/separate & 14 & 9.2 \\
\hline \multicolumn{3}{|c|}{ Number of Years working in the current organization } \\
\hline Less than 2 years & 71 & 46.4 \\
\hline $2-4$ years & 37 & 24.2 \\
\hline $5-7$ years & 24 & 15.7 \\
\hline $8-10$ years & 16 & 10.5 \\
\hline More than 10 years & 5 & 3.3 \\
\hline
\end{tabular}

Validity and Reliability of the Variables

Factor analysis is often used to better understand the underlying structure of a data matrix, to discover the most appropriate set of variables, and to create the goodness of measures to test all hypotheses (Hair, Black, Babin, Anderson \& Tatham, 2006). In this study, the principal component for factor analysis was conducted to summarize the important information included in the variables. Several statistical values were observed to establish whether the items were suitable to be factor analysed or not.

This was accomplished by examining the values of Measure of Sampling Adequacy (MSA), Kaiser-Meyer-Olkin (KMO) and Bartlett's Test of Sphericity to determine the factorability. The MSA value for the item was set above .50 and the KMO was set above .60, then factorability was assumed (Coakes, Sheridan, Stead \& Ong, 2011). Bartlett's Test of Sphericity was observed to detect the presence of significant correlation among variables. It was appropriate to proceed with factor analysis if the value of the test was large and 
significant $(p<.05)$ (Hair et al., 2006). Thus, the values of MSA, KMO and Bartlett's Test for technostress creator and work-life balance items were within the survey. Results showed that the KMO value for technostress creator was 0.917 , in which the factorability for technostress creator items was assumed. Bartlett's Test of Sphericity value (Approx. Chi-Square = $3353.954, p<.05)$ was significant. Therefore, technostress creator items were suitable to be factor analysed. Referring to work-life balance, the KMO measure of Sampling Adequacy was 0.894. This indicates that the items are interrelated and appropriate for factorization. Bartlett's Test of Sphericity value (Approx. Chi-Square $=1777.093, p<.05$ ) was significant. Hence, there are significance of correlation matrix and appropriateness of work-life balance for factor analysis.

Nonetheless, to ensure that all items in this study were used under the possible factor or variables, factor analysis was performed. There were 29 items being tested in factor analysis whereby 14 items were from independent variable and 15 items were from dependent variables. However, after screening the data, there are three items that should be deleted due to the case of cross loadings in which item that loads on two or more factors (Tabachnick \& Fidell, 2007). Table 2 shows the rotated component matrix table after deleted item for independent variables and dependent variables in this study. 
INTERNATIONAL JOURNAL OF ACADEMIC RESEARCH IN BUSINESS AND SOCIAL SCIENCES Vol. 11, No. 6, 2021, E-ISSN: 2222-6990 @ 2021 HRMARS

Table 2

Factor Analysis for each Variables Component Matrix After Deleted Item

\begin{tabular}{lccc}
\hline Variable & Component & Mean & \multicolumn{1}{c}{ SD } \\
\hline Technostress Creator & & & \\
Techno-overload 4 & .766 & 3.7124 & .84037 \\
Techno-overload 3 & .703 & 3.4967 & .96057 \\
Techno-overload 2 & .703 & 3.5752 & .91546 \\
Techno-overload 5 & .595 & 3.3464 & .99552 \\
& & & \\
Techno-invasion 2 & .789 & 3.3464 & 1.07189 \\
Techno-invasion 4 & .734 & 3.5033 & 1.02035 \\
Techno-invasion 3 & .674 & 3.3333 & 1.05755 \\
& & & \\
Techno-complexity 2 & .701 & 3.4510 & .98636 \\
Techno-complexity 4 & .656 & 3.3595 & .97747 \\
Techno-complexity 1 & .640 & 3.4837 & 1.01375 \\
Techno-complexity 5 & .625 & 3.3007 & .96030 \\
& & & \\
Work-life balance & & & \\
Work-life balance 1 & .732 & 3.7255 & .88284 \\
Work-life balance 2 & .792 & 3.3660 & 1.04347 \\
Work-life balance 3 & .802 & 3.5490 & 1.07570 \\
Work-life balance 4 & .833 & 3.3856 & 1.10098 \\
Work-life balance 5 & .656 & 3.6667 & .96655 \\
Work-life balance 6 & .821 & 3.3595 & 1.00403 \\
Work-life balance 7 & .775 & 3.5033 & .98057 \\
Work-life balance 8 & .574 & 3.6078 & .94057 \\
Work-life balance 9 & .460 & 3.3922 & 1.87867 \\
Work-life balance 10 & .802 & 3.2026 & 1.14340 \\
Work-life balance 11 & .851 & 3.4641 & 1.10040 \\
Work-life balance 12 & .644 & 3.4575 & .93883 \\
Work-life balance 13 & .790 & 3.6928 & .91968 \\
Work-life balance 14 & .836 & 3.6601 & .91165 \\
Work-life balance 15 & .834 & 3.5882 & 1.08537 \\
\hline & & & \\
\hline
\end{tabular}

Table 2 states that a few items should be deducted from this study, namely the support items number one techno-overload were deleted. Items number one techno-invasion were deleted, and items number three techno-complexity were identified to be deleted. Nevertheless, before these items were deleted, a confirmation test had been made to ensure these selected items were really needed to be discarded. A confirmation test result shows these same items were needed to be deleted as suggested by factor analysis test.

The deleted item has been deducted from the variables hence it will clarify that all items for each dimension of all variables load under its own factor which are techno-overload, techno-invasion, and techno-complexity. Thus, there were two items that have been deleted due to high cross loading and one item loaded under different component.

The reliability of the survey question was assessed by calculating Cronbach's alpha coefficient. Table 3 shows that all items in the questionnaires were reliable. The scales used 
are highly reliable for data analysis because the minimum acceptable range for Cronbach's alpha is 0.60 (Nunally, 1978).

Table 3. Descriptive statistics and reliability test $(\mathrm{N}=153)$

\begin{tabular}{lcccccc}
\hline Factors & Mean & SD & $\begin{array}{c}\text { Skewness } \\
\text { value }\end{array}$ & $\begin{array}{c}\text { Kurtosis } \\
\text { value }\end{array}$ & $\alpha$ & N of Items \\
\hline Work-life balance & 3.508 & .78617 & -.127 & -.461 & .944 & 15 \\
Techno-overload & 3.566 & .78498 & -.185 & -.055 & .909 & 5 \\
Techno-invasion & 3.361 & .91492 & -.390 & -.372 & .906 & 4 \\
$\begin{array}{l}\text { Techno- } \\
\text { complexity }\end{array}$ & 3.400 & .89648 & -.069 & -.822 & .934 & 5 \\
\hline
\end{tabular}

Thus, this study has applied Nunally's (1978) rule of thumb as a guideline to analyse the reliability of this research. If it is evident from each section of the questions that it is reliable because the value of Cronbach's alpha was 0.909 for questioning the impact of techno-overload on the work-life balance, 0.906 for questioning the impact of technoinvasion on the work-life balance, 0.934 for questioning the impact of techno-complexity on the work-life balance and 0.944 for questioning the employee work-life balance. Data distribution of variables was also conducted. The value of Skewness and Kurtosis statistics that lies between \pm 4 is acceptable (Tabachnick \& Fidell, 2014). Therefore, results showed that all variables met the acceptable range indicating the data were normally distributed. All variables have a mean value between 3.21 and 4.20 and mean score interpretation is high using 5-point Likert scale.

\section{Correlation Analysis}

Given the factors that were extracted for the technostress creator and work-life balance variables, the relationship between these variables were also examined through correlation analysis. Pearson correlation was used to analyse the strength of association between all variable in this research study. Table 4 indicates that correlation is significant and strong relationships were discovered between work-life balance and technostress creators: including techno-overload $(r=0.623 ; p<0.01)$; techno-invasion $(r=0.745 ; p<0.01)$ and techno-complexity $(r=0.750 ; p=0.01)$.

Table 4. Correlation Between Technostress Creator Towards Work-life balance.

\begin{tabular}{|l|l|c|c|c|c|}
\hline No & Variables & 1 & 2 & 3 & 4 \\
\hline 1 & Techno-overload & - & & & \\
\hline 2 & Techno-invasion & $.750^{* *}$ & - & & \\
\hline 3 & $\begin{array}{l}\text { Techno- } \\
\text { complexity }\end{array}$ & $.725^{* *}$ & $.759^{* *}$ & - & \\
\hline 4 & Work-life balance & $.623^{* *}$ & $.745^{* *}$ & $.750^{* *}$ & - \\
\hline
\end{tabular}

** correlation is significant at the 0.01 level

Therefore, the findings confirmed that there is an increase in technostress creators; including techno-overload, techno-invasion and techno-complexity, and an increase in employees struggling to attain the work-life balance. It can be concluded that all hypotheses have been supported: 


\section{Research Hypotheses}

$\mathrm{H} 1$ : There is a relationship between techno-overload and work-life balance.

$\mathrm{H} 2$ : There is a relationship between techno-invasion and work-life balance.

$\mathrm{H} 3$ : There is a relationship between techno-complexity and work-life balance.

\section{Discussion and Conclusion}

Empirical studies have shown that workers in private sectors are faced with constant technostress resulting from global environmental changes that emerged with consequences of intensified inter-organizational / interpersonal competition and technological development; the ignorant managers' attitude towards the necessity for technology capability enhancing for employees' performance upgrading; and the adverse behaviour of the employees themselves. However, this current study was designed to further examine the relationship between technostress creator (techno-overload, techno-invasion and technocomplexity) and work-life balance.

The results indicate that the technostress creator (techno-overload, techno-invasion and techno-complexity) exhibited a significant and strong relationship with work-life balance. This finding supports a previous study conducted by Murray and Rotis (2017) which emphasized that employees are constantly connected to technology, either via hand phone or email, even during holiday or private time spent with family members, in their effort to answer urgent tasks forwarded by the employer regardless of time. This has a direct contribution to quality-of-life decrease. In this study, techno-complexity showed the strongest relationship and most significant effect towards work-life balance. Such effect is assumable from the hardship employees must endure each time new application of technologies is introduced to their working environment. The learning process may consume months to be completed. While technology itself may bring a positive impact to productivity, the wrong method of application could in reverse cause negativity to employees' work-life balance (Okolo, 2018).

For techno-overload, the improvement of communication technology (depending of its usage) has facilitated the increase amount of work, work phase and even changed the work habits where individuals working anytime and anywhere and cannot handle time with more efficiency end up with decrease in work-life balance (Ingusci et al., 2021). It should be noted that technostress will lead to better performance and eventually deteriorate work-life balance. Both employees and managers in the organizations need to understand that technology eliminates the need for employees to follow a balanced work and leisure regime. Particularly managers need to be more responsible towards employees' work-life balance when planning organization's work activities and the workload of each employee.

This research, like others, is with its limitation. First, the researchers only focused on a selected private sector area and the population chosen as respondents was limited to employees in that particular sector. Second, the research focuses only on three variables of technostress creator (techno-overload, techno-invasion and techno-complexity). Future research should further explore to identify other possible technostress creator to industry in this country and expand the geographical locations of the research to other states in Malaysia. The research findings should then be shared with all private sector industries to raise awareness of the importance of sustaining work-life balance among employees. 


\section{Acknowledgment}

The authors would like to express their sincere gratitude to the Institute of Business Excellence and the Faculty of Business and Management, Universiti Teknologi MARA (UiTM) Shah Alam and Cawangan Selangor, Kampus Puncak Alam, for their kind support and contribution.

\section{Reference}

Bayer, J. B., Campbell, S. W., \& Ling, R. (2015). Connection Cues: Activating the Norms and Habits of Social Connectedness. Communication Theory, 26, 128-149.

Benamati, J. L. A. L. (2001). The Effect of Rapid IT Change on The Demand for Training. Proceedings of ACM Special Interest Group on Computer Personnel Research, San Diego, CA.

Caruso, C. C. (2006). "Possible Broad Impacts of Long Work Hours", Industrial Health, Vol. 44 No. 4, pp. 531-536.

Capitano, J., \& Greenhaus, J. H. (2018). When work enters the home: Antecedents of role boundary permeability behavior. Journal of Vocational Behavior, 109, 87-100.

Choi, H. S., Kim, T. G., \& Cho, Y. G. (2011). A Study on the Effects of Technostress on Flow and Continuous Use of Smartphone. Cyber Journal of Korean Institute of Information Technology, 8, 175-184.

Coakes. S. J. (2013), SPSS: Analysis without Auguish Using SPSS Version 20.0 for Windows Autralia: Milton, John Wiley \& Son, Ltd.

Cohen, J. (1988). Set correlatiokon and contingency tables. Applied Psychological Measurement, 12(4), 425-434.

Derks, D., ten Brummelhuis, L. L., Zecic, D., \& Bakker, A. B. (2014). Switching on And off Does Smartphone Use Obstruct The Possibility To Engage In Recovery Activities. European Journal of Work and Organizational Psychology, 23(1), 80-90.

Foy, T., Dwyer, R. J., Nafarrete, R., Hammoud, M. S. S., \& Rockett, P. (2019). Managing job performance, social support and work-life conflict to reduce workplace stress. International Journal of Productivity and Performance Management.

Gajendran, R. S., \& Harrison, D. A. (2007). The Good, The Bad, and The Unknown About Telecommuting: Meta-Analysis of Psychological Mediators and Individual Consequences. Journal of Applied Psychology, 92(6), 1524-1541.

Gallivan, M. J. (2004). Examining IT Professionals' Adaptation to Technological Change: The Influence of Gender and Personal Attributes. The Data Base for Advances in Information Systems, 35(3).

Geetanjali, P., \& Rao, K. A. (2020). Effect of Job Stress On Work-life balance (WLB) Of Women In IT Sector. Studies in Indian Place Names, 40(6), 39-50.

Gragnano, A., Simbula, S., \& Miglioretti, M. (2020). Work-Life Balance: Weighing the Importance of Work-Family and Work-Health Balance. International journal of environmental research and public health, 17(3), 907.

Greenhaus, J. H., Ziegert, J. C. \& Allen, T. D. (2012). When family-supportive supervision matters: Relations between multiple sources of support and work-family balance. Journal of Vocational Behavior, Volume 80, pp. 266-275

Greenhaus, J. H., Collins, K. M., \& Shaw, J. D. (2003). The relation between work-family balance and quality of life. Journal of vocational behavior, 63(3), 510-531. 
Haar, J. M. (2013). Testing a new measure of work-life balance: A study of parent and nonparent employees from New Zealand. The International Journal of Human Resource Management, 24(17), 3305-3324.

Hair, J. F., Black, W. C., Babin, B. J., Anderson, R. E., \& Tatham, R. L. (2006), Multivariate Data Analysis (6 $6^{\mathrm{TH}}$ ED.) New Jersey: Prentoce Hall.

Ibrahim, H., \& Yusoff, Y. M. (2015). User Characteristics As Antecedents Of Techno Stress Towards EHRM: From Experts' Views. Procedia-Social and Behavioral Sciences, 172, 134-141.

Ingusci, E., Signore, F., Giancaspro, M. L., Manuti, A., Molino, M., Russo, V., \& Cortese, C. G. (2021). Workload, Techno Overload, and Behavioral Stress During COVID-19 Emergency: The Role of Job Crafting in Remote Workers. Frontiers in Psychology, 12, 1141

Jena, R. (2015). "Technostress In ICT Enabled Collaborative Learning Environment: An Empirical Study Among Indian Academician." Computers in Human Behavior 51: 1116-1123.

Kupersmith, J. (1992). Technostress and The Reference librarian. Reference Services Review, 20(7), 14.

Lei, C. F., and Ngai, E. W. (2014). "The Double-Edge Nature of Technostress on Work Performance: A Research Model and Research Agenda", Proceedings of 35th International Conference on Information Systems, Auckland.

Lutz, S., Schneider, F. M., \& Vorderer, P. (2020). On The Downside of Mobile Communication: An Experimental Study About The Influence Of Setting-Inconsistent Pressure On Employees' Emotional Well-Being. Computers in Human Behavior, 105, 106216.

Murray, W. C., \& Rostis, A. (2007). Who is Running the Machine? A Theoretical Exploration of Work Stress and Burnout of Technologically Tethered Workers, Journal of Individual Employment Rights 12(3): 249-263.

Nunaly, J. C. (1978), Psychometric Theory (2nd ed) New York: McGraw. Hill

Okebaram, and Moses, S. (2013). Minimizing the Effects of Technostress in Today's Organization. International Journal of Emerging Technology and Advanced Engineering, 3(11), 649-658

Okolo, D. (2018). An Exploration of The Relationship Between Technostress, Employee Engagement and Job Design from The Nigerian Banking Employee's Perspective. Management dynamics in the knowledge economy, vol.6 no.4, pp.511-530.

Orwa, P. A., \& Nyangau, A. (2020). Effects of work-life balance practices on organization performance in Homa bay county referral hospital, Kenya.

Raisiene, A. G., \& Jonusauskas, S. (2013). Silent issues of ICT era: impact of techno-stress to the work and life balance of employees. Entrepreneurship and sustainability issues, 1, 108-115

Rosen, L. D., \&Weil, M. M. (2002).Technostress: Coping with technology@work@ home@ play (pp. 29-32). New York: Wiley.

Roscoe, J. T. (1975). Fundamental Research Statistics For The Behavioral Sciences by John T. Roscoe (2nd ed.). New York: Holt, Rinehart and Winston.

Salkind, N. J. (2012). Exploring Research. Second Edition. New Jersey: Pearson Education. Salkind, N. J. (2014). Exploring Research. Second Edition. New Jersey: Pearson Education. 
Sarabadani, J., Carter, M., \& Compeau, D. (2020). 10 Years of Research on Technostress Creators and Inhibitors: Synthesis and Critique. American Conference on Information Systems (AMCIS).

Salo, M., Pirkkalainen, H., Makkonen, M., and Hekkala, R. (2018). Distress, Eustress, Or No Stress?: Explaining Smartphone Users Different Technostress Responses. International Conference on Information Systems, Association for Information Systems (AIS).

Sekaran, U., \& Bougie, R. (2011). Research Methods for Business: A Skill Building Approach. United Kingdom: Wiley.

Stich, J.-F., Tarafdar, M., Stacey, P., and Cooper, S. C. (2019). "Appraisal of Email Use as a Source of Workplace Stress: A Person-Environment Fit Approach." Journal of the Association for Information Systems 20(2).

Suh, A., and Lee, J. (2017). Understanding teleworkers' technostress and its influence on job satisfaction. Internet Research, 27(1), 140-159.

Tabachnick, B. G., \& Fidell, L. S. (2007). In Using Multivariate Statistics (5th ed.). New York, NY: Pearson.

Tan, T. Y. (2019). Relation Of Work-Life Balance To Counterproductive Work Behavior And Turnover Intention Among Malaysian Employees. In 2nd International Conference On Intervention And Applied Psychology. Atlantis Press.

Tarafdar, M., Tu, Q., Ragu-Nathan, T. S., and Ragu-Nathan, B. S. (2011). “Crossing to The Darkside:examining antecedents and consequences of technostress",Communicationsof the ACM,Vol.54 No. 9, pp. 113-120.

Thakur, M. B., Shah, H., \& Bhat, N. (2020). Relationship between Work-Life Balance and Job Satisfaction. Our Heritage, 68(1), 1248-1264

White, J., Behrend, T., \& Siderits, I. (2020). 4 Changes in Technology. The Cambridge Handbook of the Changing Nature of Work, 69.

Wong, L. P., Alias, H., Bhoo-Pathy, N., Chung, I., Chong, Y. C., Kalra, S., \& Shah, Z. U. B. S. (2020). Impact of migraine on workplace productivity and monetary loss: a study of employees in banking sector in Malaysia. The Journal of Headache and Pain, 21(1), 111. 